\title{
Web Portals for Patients With Chronic Diseases: Scoping Review of the Functional Features and Theoretical Frameworks of Telerehabilitation Platforms
}

Yuh Morimoto $^{1}$, PhD; Tetsuya Takahashi ${ }^{2,3}$, PT, MSc, PhD; Ryuichi Sawa ${ }^{2}$, PT, MSc, PhD; Masakazu Saitoh ${ }^{2}$, PT, MSc, PhD; Tomoyuki Morisawa ${ }^{2}$ PT, MSc, PhD; Nobuyuki Kagiyama ${ }^{3,4}$, MD, PhD; Takatoshi Kasai ${ }^{3,4}$, MD, PhD; Birthe Dinesen $^{5}, \mathrm{MSc}$, PhD; Malene Hollingdal ${ }^{6}, \mathrm{MD}, \mathrm{PhD}$; Jens Refsgaard ${ }^{6}$, MD, PhD; Hiroyuki Daida ${ }^{1,2,3,4}$, MD, $\mathrm{PhD}$

${ }^{1}$ Faculty of Health Science, Juntendo University, Tokyo, Japan

${ }^{2}$ Department of Physical Therapy, Faculty of Health Science, Juntendo University, Tokyo, Japan

${ }^{3}$ Department of Digital Health and Telemedicine Research and Development, Faculty of Health Science, Juntendo University, Tokyo, Japan

${ }^{4}$ Department of Cardiovascular Biology and Medicine, Juntendo University Graduate School of Medicine, Tokyo, Japan

${ }^{5}$ Laboratory for Welfare Technologies - Telehealth \& Telerehabilitation, Sport Sciences - Performance and Technology, Department of Health Science and Technology, Aalborg University, Aalborg, Denmark

${ }^{6}$ Department of Cardiology, Regional Hospital in Viborg, Viborg, Denmark

\section{Corresponding Author:}

Hiroyuki Daida, MD, PhD

Faculty of Health Science

Juntendo University

2-1-1 Hongo Bunkyo-ku

Tokyo, 1138421

Japan

Phone: 81338133111 ext 3900

Fax: 81338121781

Email: daida@juntendo.ac.jp

\section{Abstract}

Background: The COVID-19 pandemic has required an increased need for rehabilitation activities applicable to patients with chronic diseases. Telerehabilitation has several advantages, including reducing clinic visits by patients vulnerable to infectious diseases. Digital platforms are often used to assist rehabilitation services for patients in remote settings. Although web portals for medical use have existed for years, the technology in telerehabilitation remains a novel method.

Objective: This scoping review investigated the functional features and theoretical approaches of web portals developed for telerehabilitation in patients with chronic diseases.

Methods: PubMed and Web of Science were reviewed to identify articles associated with telerehabilitation. Of the 477 nonduplicate articles reviewed, 35 involving 14 portals were retrieved for the scoping review. The functional features, targeted diseases, and theoretical approaches of these portals were studied.

Results: The 14 portals targeted patients with chronic obstructive pulmonary disease, cardiovascular, osteoarthritis, multiple sclerosis, cystic fibrosis diseases, and stroke and breast cancer survivors. Monitoring/data tracking and communication functions were the most common, followed by exercise instructions and diary/self-report features. Several theoretical approaches, behavior change techniques, and motivational techniques were found to be utilized.

Conclusions: The web portals could unify and display multiple types of data and effectively provide various types of information. Asynchronous correspondence was more favorable than synchronous, real-time interactions. Data acquisition often required assistance from other digital tools. Various functions with patient-centered principles, behavior change strategies, and motivational techniques were observed for better support shifting to a healthier lifestyle. These findings suggested that web portals for telerehabilitation not only provided entrance into rehabilitation programs but also reinforced participant-centered treatment, adherence to rehabilitation, and lifestyle changes over time. 
(J Med Internet Res 2022;24(1):e27759) doi: 10.2196/27759

\section{KEYWORDS}

telerehabilitation; web portal; chronic disease; monitoring/data tracking function; patient-centered care

\section{Introduction}

Chronic diseases are the leading causes of death worldwide. The World Health Organization has reported that chronic diseases are responsible for almost $60 \%$ of deaths worldwide [1]. Studies show evidence of the effectiveness of rehabilitation for patients with chronic disease; however, rehabilitation programs are generally underused [2,3]. The major barriers to participation in a rehabilitation program include inconvenient timing, travel and transport issues, and lack of perceived benefit [4]. Currently, rehabilitation services are facing even more difficulty because of the COVID-19 pandemic. Conventional clinic-based rehabilitation programs have been suspended as a result of physical distancing recommendations and a shortage of health care services [5,6]. Patients with chronic diseases are more likely to develop severe conditions than patients without chronic diseases, thus visiting clinics is considered to be a risk to be avoided by patients [7]. Telerehabilitation can address such obstacles, even during the COVID-19 pandemic.

Telerehabilitation is defined as rehabilitation activities performed using information provided by communication technologies over a distance [8]. Telerehabilitation for patients with chronic diseases may consist of many components, for example, exercise instruction, education, better communication, and self-management training [9-11]. Digital platforms are often used to assist rehabilitation services for patients in remote settings [12-14], and web portals are one of the potential technologies. The term "portal (computing)" has been described as a website that is used as a gateway to the internet, where information useful to a person interested in particular topics has been gathered [15]. A web portal in clinical use has been described as a kind of electronic health record that permits patients to access their records or communicate with their health care professionals $[16,17]$. Furthermore, the US government describes a web portal as "a secure online website that gives patients convenient, 24-hour access to personal health information from anywhere with an internet connection" [18]. Taking into account the personal nature of the information, access is often limited to authorized people in a secure and confidential setting [19]. To encourage patient engagement and provide benefits, web portals are recommended to follow the principle of patient-centered care [20]. The primary concept of patient-centered care is that patient values guide clinical decisions [21]. The 6 factors defined as components of patient-centered care are (1) respect for patients' values, preferences, and expressed needs; (2) coordination and integration of care; (3) information, communication, and education; (4) physical comfort; (5) emotional support; and (6) involvement of family and friends [22].

Web portals have the potential to be a core digital component for patient-centered telerehabilitation, however, relatively few have been adapted for telerehabilitation [23], and few studies to date have analyzed the use of web portals for telerehabilitation in an international context. It is not known whether there are unique characteristics in web portals developed for telerehabilitation targeting chronic diseases rather portals designed for other medical purposes. For these reasons, a scoping review was conducted to gather knowledge about what has been designed and tested in clinical practice, as well as to identify any existing gaps in knowledge. The search strategy according to population, concept, and context elements was as follows: P, telerehabilitation participants with chronic disease; $\mathrm{C}$, web portals developed for telerehabilitation, functional features, theoretical approaches, behavior change techniques (BCT), motivational techniques (MTs), and mode of delivery; $\mathrm{C}$, any gender, age, or region. The following research question was formulated to guide this review: What are the functional features and theoretical approaches of web portals developed for telerehabilitation programs in patients with chronic diseases, as well as any characteristics that can be observed through the investigations?

\section{Methods}

\section{Study Design}

This study was designed to map the functional features of web portals utilized for telerehabilitation targeting chronic diseases. Although systematic reviews are preferred for answering clearly defined questions, a scoping review method is considered useful for answering broad questions [24]. The scoping review protocol in this study was developed using the guidelines provided by the Preferred Reporting Items for Systematic Reviews and Meta-analysis Extension for Scoping Reviews (PRISMA-ScR) checklist [24,25]. With the cooperation of an experienced university librarian, multiple databases were searched, ensuring the appropriateness of the search strategy. The final version of the protocol is available from a protocol registry [26].

\section{Identification and Selection of the Relevant Articles}

A literature search of the international online bibliographic databases PubMed [27] and the Web of Science [28] was performed on May 17, 2021. The search formula used for the PubMed search engine was ((telerehabilitation) AND (chronic)) OR ((telerehabilitation) AND ((portal) OR (web-based) OR (digital platform) OR (online platform) OR (internet-based))). Because the definitions of web portals for telerehabilitation participants were not determined in a common context, digital platforms used for telerehabilitation were reviewed with the principal concepts of web portals described above, such as (1) web-based application, (2) allows the participants 24-hour access, and (3) containing useful rehabilitation-related functions for participants. To extract core components of web portals for telerehabilitation, portals developed for purposes other than telerehabilitation were excluded, as were clinician portals. To focus on the essential features, telerehabilitation portals targeting anything other than chronic diseases were also excluded. Web applications designed for a single purpose, web services with 
limited time of access, and digital platforms based on native applications (eg, iOS and Android apps and PC applications) were excluded based on the definitions of web portals described above. Abstracts of the selected studies were reviewed by the team members according to the inclusion/exclusion criteria. Review articles, editorials, conference reports, and interviews were also excluded, whereas protocols were included.

Data extraction and charting were performed according to Arksey and O'Malley's guideline [29]. Data from the selected articles were extracted with the following modules: portal name, project name, country, functional features, targeted chronic diseases, language, and other systems required for the telerehabilitation service. Theories and models used in a study were investigated as well as BCTs, MTs, and mode of delivery. Several articles were found to describe the same telerehabilitation project. The names of the projects and web

portals, as well as the authors, institutions, and trial registration numbers, were used to identify telerehabilitation projects described in multiple articles.

\section{Results}

\section{Overview}

Of the 644 articles initially identified by keywords, 477 remained after the removal of duplicates. An additional 5 articles were found through manual searching. Figure 1 shows the flow diagram of the article identification process. The titles and abstracts of these 482 nonduplicated articles were reviewed during the initial screening phase, resulting in the identification of 145 articles for full-text screening. Of these 145 articles, 35 articles with 14 platforms satisfied the criteria and were included in the analysis. Full reasons for exclusion are shown in Figure 1 .

Figure 1. Flow diagram of article identification.
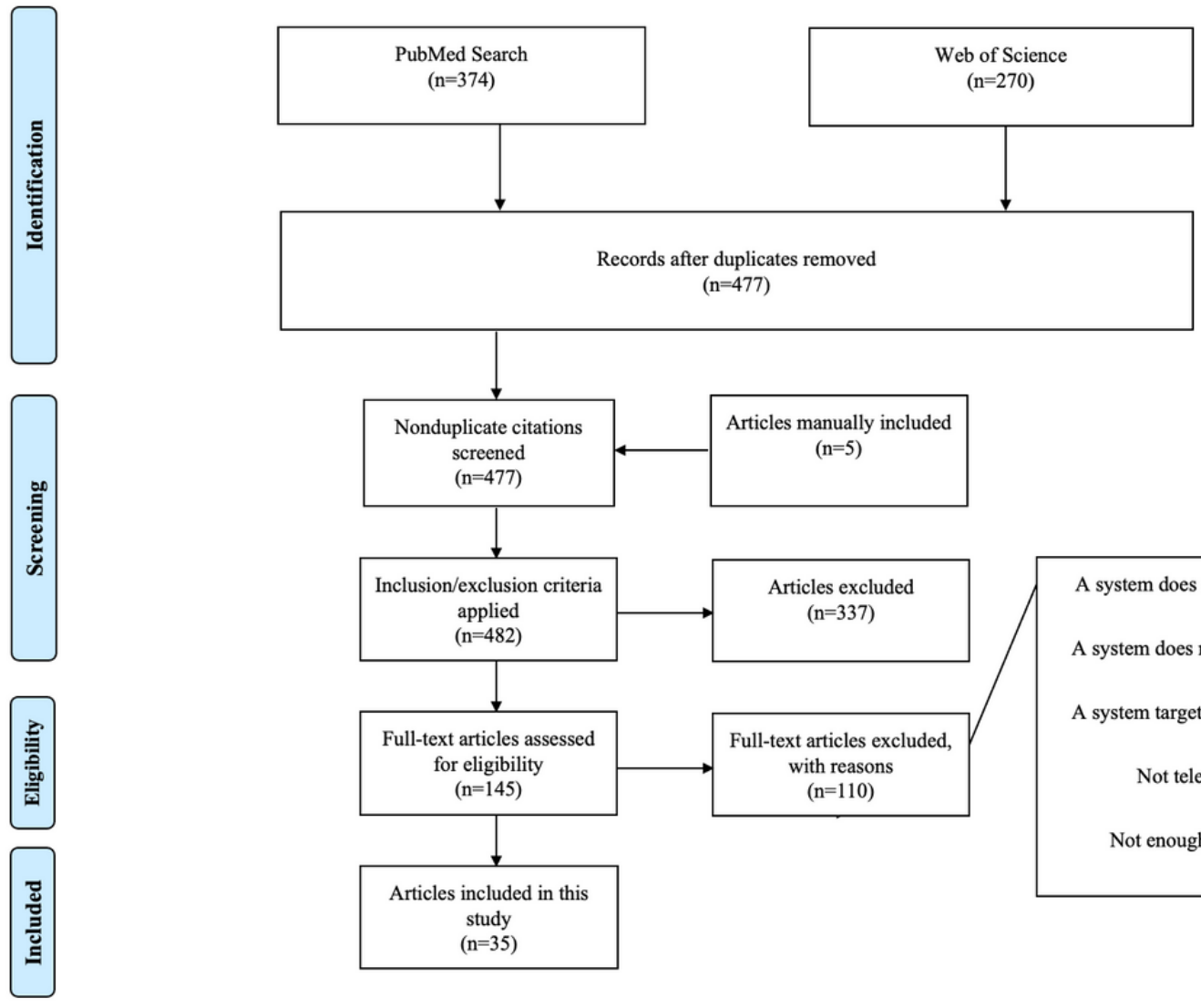

removed

477)

\section{Functional Features of Telerehabilitation Portals}

Five portals were for patients with chronic obstructive pulmonary disease (COPD) [30-43], 3 were for patients with cardiovascular diseases [44-49], 2 for multiple sclerosis [50,51], and 1 each for patients with osteoarthritis [52-56], cystic fibrosis [57-59], and stroke [60], and breast cancer survivors [61-64]. These 14 portals were implemented with multiple functions. Monitoring/data tracking functions and communication platforms were the most common features, provided by 11 and 10 portals, respectively. Monitoring/tracking functions foster self-management skills in patients by gaining knowledge and awareness of their health and active involvement in rehabilitation programs $[30,37,46]$. Communication functions take various forms, including text messaging systems, web forums, and videoconferencing. Exercise instruction function with audiovisual contents was emphasized in 9 portals, and diary/self-report function was found in 9 portals, being used for patients to share their rehabilitation reports and experience with health care team members. Six portals allowed relatives to participate in the rehabilitation program with permission of the patient. Education was also frequently found with 5 portals. Patient-reported outcomes (PROs) data and goal settings can be collected or determined through specifically designed systems [55], as well as through diary or communication functions $[48,50,64]$. Two portals embedded audiovisual contents about 
other patients and their family members talking about their experiences of rehabilitation (narrative of others) [46,48]. Although monitoring is one of the major functions, portals often require assistance from other digital tools $[30,35,41,44,50]$ or extra effort of manual operations [49,57]. The most dominant security measure was an individual, password-protected system. Furthermore, ActivOnline protects user data and privacy by employing security measures (eg, 128-bit SSL security) to provide encrypted data transfer [59], and "web application" (portal 8) employed a 2-factor log-in system with participants' private mobile phone [49]. The summary of functional features and the 14 portals are shown in Table 1 and Figure 2. Detailed descriptions of each portal are given in Multimedia Appendix 1 . 
Figure 2. A summary of functional features and the 14 portals. A colored circle indicates a functional feature. The number in a circle denotes the number of portals that employ the functional feature. A colored circle with a dotted line is associated with the principle of patient-centered care. Yellow boxes on a gray circle indicate a web portal. The number in parenthesis denotes the number of functional features the portal implemented. P1: ActiveHeart; P2: ActivOnline; P3: e-Exercise; P4: HeartPortal; P5: IBMS; P6: “A web portal”; P7: TELEKAT portal; P8: "A web application”, P9: "A webpage for self-management"; P10: e-CUIDATE system; P11: "A web portal”; P12: "A web platform; P13: LifeCIT website; P14: "A website". IBMS: Integrated Care Portal Multiple Sclerosis; TELEKAT: telehomecare, chronic patients, and the integrated health care system; P: portal; PROs: patient reported outcomes.
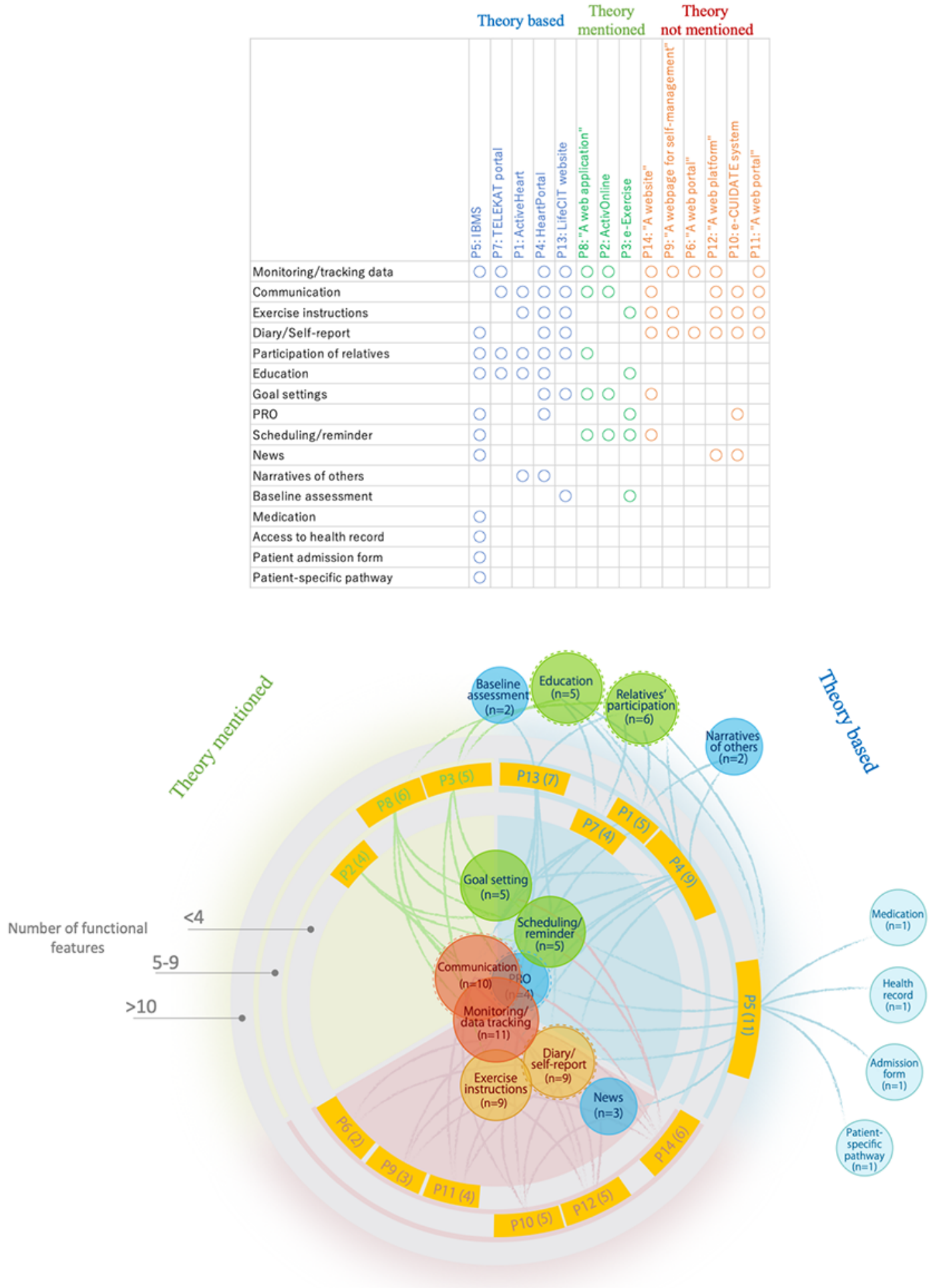

Theoretical approach not mentioned

Some functional features are considered to be associated with the principle of patient-centered care. Respect for patients' values can be attempted by PRO, diary function, and the participatory design process, which several portals followed
$[36,45,47,50]$. Communication and education functions can provide coordination and integration of care, and the function of the relatives' participation is associated with involvement of family and friends. 
Table 1. A list of included studies.

\begin{tabular}{lllll}
\hline Portal name and references & Project name & Diseases & Functional features & Required additional systems \\
\hline Portal 1: ActiveHeart & TTP $^{\mathrm{a}}$ & Heart disease & $\begin{array}{l}\text { Communication, exercise instructions, } \\
\text { education, participation of relatives, } \\
\text { narratives of others }\end{array}$ & $\begin{array}{l}\text { The shared care platform, } \\
\text { Mymanomer, Fitbit, sphygmo- } \\
\text { male }\end{array}$
\end{tabular}

Dinesen et al [44]

Dinesen et al [45]

Melholt et al [46]

Portal 2: ActivOnline

Cox et al [57]

Liacos et al [58]

Cox et al [59]

Portal 3: e-Exercise e-Exercise

Knee/hip osteoarthritis

Kloek et al [52]

Kloek et al [53]

Kloek et al [54]

de Vries et al [55]

Bossen et al [56]

Portal 4: HeartPortal Future patient Heart failure

Joensson et al [47]

Dinesen et al [48]

Portal 5: IBMS -

Multiple sclerosis

Voigt et al [50]

Portal 6: "A web portal"

-

COPD

Tabak et al [30]

\section{Portal 7: TELEKAT ${ }^{i}$ por- TELEKAT COPD}

tal

Dinesen et al [31]

Haesum et al [32]

Dinesen et al [33]

Jensen et al [34]

Dinesen et al [35]

Dinesen et al [36]
Exercise instructions, education,

Face-to-face sessions PROs $^{\mathrm{e}}$, scheduling/reminder, baseline assessment

Monitoring/tracking data, communication, exercise instructions, diary, education, participation of relatives, goal settings (via communication and diary function), PROs, narratives of others

Monitoring/tracking data, diary, education, participation of relatives, PROs (via diary function), scheduling/reminder, news, medication, access to a health care record (multiple sclerosis care record), patient administration form, patient-specific pathways

Monitoring/tracking data, diary

Activity coach (smartphone

Monitoring/tracking data, communi- MyMedic/MyMedicPlus, cation, education (via communication scale, sphygmomanometer, function), participation of relatives and accelerometer)

Sphygmomanometer, scale, data transmitter, step counters, sleep sensor, iPad

$\mathrm{MSDS}^{3 \mathrm{Dh}}$, multiple sclerosis case record oximeter, spirometer 


\begin{tabular}{cllll}
\hline Portal name and references & Project name & Diseases & Functional features & Required additional systems \\
\hline \multicolumn{1}{c}{ Huniche et al [37] } & & Coronary artery disease & $\begin{array}{l}\text { Monitoring/tracking data, communi- } \\
\text { cation, participation of relatives, goal } \\
\text { setting, scheduling/reminder }\end{array}$ & $\begin{array}{l}\text { Mio alpha, hip-worn ac- } \\
\text { Portal 8: "A web applica- } \\
\text { tion" }\end{array}$ \\
$\begin{array}{l}\text { Smart- } \\
\text { CareCAD }\end{array}$ & & COPD & $\begin{array}{l}\text { Monitoring/tracking data, exercise } \\
\text { instructions, diary }\end{array}$ & $\begin{array}{l}\text { Treadmill, iPad, iPad holder, } \\
\text { web conference application, } \\
\text { pulse oximeter }\end{array}$
\end{tabular}

Zanaboni et al [38]

Hoaas et al [39]

Zanaboni et al [40]

Portal 10: e-CUIDATE e-CUIDATE Breast cancer survivors
system

Ariza-Garcia et al [61]

Galiano-Castillo et al

[62]

Galiano-Castillo et al

[63]

Galiano-Castillo et al

[64]

Portal 11: "A web portal” -

Tabak et al [41]
Portal 12": "A web plat- $\quad-\quad$ Multiple sclerosis
form"

Eguiluz-Perez and Garcia-Zapirain [51]
Monitoring/tracking data, communication, exercise instructions, diary

Monitoring/tracking data, communication, exercise instructions, diary, news

Communication, exercise instructions, Telephone call diary, PROs (via communication function), news camera $^{\mathrm{j}}$
Activity coach (smartphone and accelerometer)

An ad hoc tracking system for determination of posture, ToF

Monitoring/tracking data, communication, exercise instructions, diary, participation of relatives, goal setting, baseline assessment

Monitoring/tracking data, communication, exercise instructions, diary, goal setting, scheduling/reminder
Treadmill, iPad, iPad holder, web conference application, pulse oximeter

Hoaas et al [42]

Zanaboni et al [43]

${ }^{\mathrm{a}}$ TTP: teledialog telerehabilitation program.

${ }^{\mathrm{b}}$ Interviews, stories, and experiences of other patients or relatives who have the same disease.

${ }^{\mathrm{c}}$ ActionPACT: the active online physical activity in the cystic fibrosis trial.

${ }^{\mathrm{d}}$ COPD: chronic obstructive pulmonary disease.

${ }^{\mathrm{e}}$ PROs: patient-reported outcomes.

${ }^{\mathrm{f}}$ IBMS: integrated care portal multiple sclerosis.

$\mathrm{g}_{\text {Not specified. }}$

${ }^{\mathrm{h}}$ Integration of the multiple sclerosis documentation system.

${ }^{\mathrm{i}}$ TELEKAT: telehomecare, chronic patients, and the integrated health care system.

${ }^{\mathrm{j}}$ Time-of-flight camera.

${ }^{\mathrm{k}}$ Constraint-induced therapy. 


\section{Theoretical Approaches of Telerehabilitation Portals}

Theoretical approaches were observed in 8 portals. Among them, eHealth literacy described by Norman and Skinner [65], Wenger's Communities of Practice [66], and Self-Determination Theory [67] were used for both development process and qualitative usability evaluation [31,44,47,48]. The model of eHealth literacy was first used in the qualitative data analysis in ActiveHeart [46], and then employed in HeartPortal to foster participants' empowerment [48]. Communities of practice focus on people who share a common interest or concern and interact regularly, with learning taking place during interpersonal interactions [66]. The theory influenced the design of portals as facilitating communication and knowledge-sharing functions among participants and patients with chronic diseases in the ActiveHeart and telehomecare, and the integrated health care system (TELEKAT) portals [31,44]. The Self-Determination Theory takes into account intrinsic and extrinsic motivation with 3 basic human needs: autonomy, competence, and relatedness [67]. HeartPortal includes a graphical function that displays charts of each participant's physical data [48]. Participants who monitor their condition using detailed charts are expected to gain autonomy and competence. Relatives' participation upon patient's permission is included in several portals, and it is in the context of relatedness in HeartPortal. Pathway-based care model-implemented integrated care portal multiple sclerosis (IBMS) is an approach that provides a patient with a complete picture of his/her disease progression and the current state of an evidence-based treatment strategy [50,68]. By using this model, milestones of the treatment are defined, and shared decision making between patients and the multidisciplinary care team is expected to be induced [50]. Person-based approach for designing successful digital interventions [69] was the method used to guide the development phase of LifeCIT's website [60].

Some studies were not "theory based" but introduced theories in their study concept, thus we considered them as "theory mentioned." Cognitive behavior principles were mentioned in 3 studies [49,53,57], where 1 study [49] briefly mentions theory linking to relapse prevention. Operant conditioning was associated with time-contingent exercise activity in e-Exercise [56]. On the contrary, "A webpage for self-management" (portal 9) stated their study was empirically based. Moreover, e-Exercise, "A web portal" (portal 11), and "A website" (portal 14) used empirical data of their previous trials $[41,56]$.

The BCTs and MTs were identified by the authors' descriptions in the included articles, as well as referring to a taxonomy of BCTs proposed by Abraham and Michie [70]. The incorporation of several BCTs was reported to be more effective than interventions that incorporated fewer techniques [71]. Relatives' participation and goal settings were commonly found in portals that took theoretical approaches. The general purpose of BCTs is to better support patients shifting to a healthier lifestyle. Note that a technique mentioned as BCT in one study can be implemented in another study without being stated as a BCT purpose.

Mode of delivery is also known to influence behavior [71]. It is obvious that all 14 portals are internet-based programs, of which ActivOnline, "A web application" (portal 8), e-CUIDATE, and "A website" (portal 14) chose this mode of delivery with the expectation of better treatment results compared with conventional center-based treatment $[43,49,57,61]$. As a synchronous communication, 2 portals embedded a videoconferencing function, which is used for consultations rather than exercise instructions. Asynchronous physical activity was intentionally chosen for better adherence to the exercise in several studies $[39,41,43,56,64]$. Although 2 interventions applied synchronous group exercises in addition to asynchronous exercises thorough a videoconferencing application apart from a portal $[39,43]$, no functional features of the 14 portals were used for synchronous exercise instructions. The LifeCIT website has gaming contents for poststroke exercise [60]. While the portals that took the theoretical approach tend to have more BCTs, the number of modes of delivery did not differ between portals with or without a theoretical approach. Figure 3 summarizes the theoretical approaches, BCTs, MTs, and modes of delivery employed in the 14 portals. 
Figure 3. Theoretical approaches, BCTs, MTs, and modes of delivery employed in the 14 portals. Yellow square, theory applied; light yellow squares, theory or model mentioned without specifies on the mode of implication; green squares, BCT applied; light green squares, BCT mentioned without specifies on the mode of implication; green circles, through an additional system; orange squares, mode of delivery applied; orange circles, through an additional system including another digital platform used simultaneously, video consultation with HCP, or face-to-face session as part of the intervention; I: theory based; II: theory mentioned; III: theory not mentioned; BCT: behavior change technique; HCP: health care provider; IBMS: integrated care portal multiple sclerosis; MT: motivational technique; MoD: mode of delivery; TELEKAT: telehomecare, chronic patients, and the integrated health care system.

\begin{tabular}{|c|c|c|c|c|c|c|c|c|c|c|c|c|c|c|c|}
\hline & & \multicolumn{8}{|c|}{ II } & \multicolumn{6}{|c|}{ III } \\
\hline & & $\begin{array}{l}\sum_{0}^{\infty} \\
\ddot{n} \\
\frac{\vec{n}}{0} \\
\stackrel{0}{0}\end{array}$ & 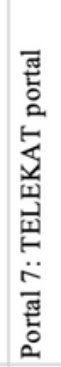 & 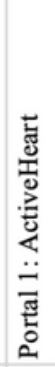 & 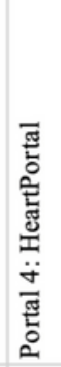 & 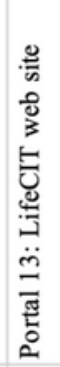 & 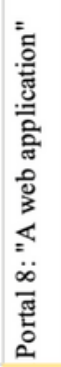 & 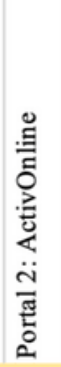 & 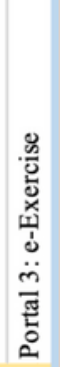 & 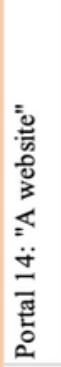 & 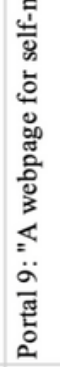 & 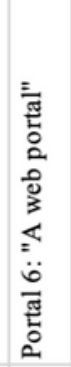 & 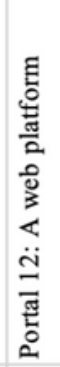 & 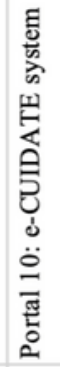 & 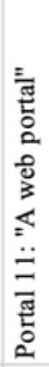 \\
\hline Cognitive behavior principles & Theory & & & & & & & & & & & & & & \\
\hline Communities of Practice & Theory & & & & & & & & & & & & & & \\
\hline Self-Determination Theory & Theory & & & & & & & & & & & & & & \\
\hline eHealth literacy & Theory & & & & & & & & & & & & & & \\
\hline Person-based approach & Theory & & & & & & & & & & & & & & \\
\hline Pathway-based care model & Theory & & & & & & & & & & & & & & \\
\hline Operant conditioning & Theory & & & & & & & & & & & & & & \\
\hline Self-monitoring/self-management & BCT & & & ○ & & & & & & & & & & & \\
\hline Feedback & BCT & & & ○ & & & ○ & & & & & O & & & \\
\hline Exercise instructions & BCT & & O & & & & & & & & & & & & \\
\hline Disease-related information & BCT & & & & & & ○ & & & & & & & & O \\
\hline Relapse prevention & BCT & & & & & & & & & & & & & & \\
\hline Shared decision making & MT & & & & & & & & & & & & & & \\
\hline Relatives' participation & MT & & & & & & & & & & & & & & \\
\hline Goal setting/reviewing & BCT & & & 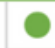 & & & & & O & & & & & & \\
\hline Narratives of others & MT & & & & & & & & & & & & & & \\
\hline Motivational interviewing & BCT & & & & & & ○ & & & & & & & & \\
\hline Graded activity & BCT & & & & & & & & & & & & & & \\
\hline Internet-based program & MoD & & & & & & & & & & & & & & \\
\hline Asynchronous physical activity & MoD & & ○ & & & & & & & & & & & & \\
\hline Audiovisual contents & MoD & & & & & & & & & & & & & & \\
\hline Text-based communication & MoD & & & & & & & & & & & & & & \\
\hline Individually modified exercises & MoD & & & & & & & & & & & & & & \\
\hline Blended care & MoD & & & & & & & & & & & & & & \\
\hline Video consultation & MoD & & & & & & & & & ○ & ○ & & & & \\
\hline Group training & MoD & & & & & & & & & ○ & ○ & & & & \\
\hline Synchronous physical activity & MoD & & & & & & & & & ○ & ○ & & & & \\
\hline Serious games & MoD & & & & & & & & & & & & & & \\
\hline
\end{tabular}




\section{Discussion}

\section{Principal Findings}

The objective of this scoping review was to investigate functional features and theoretical approaches of web portals developed for telerehabilitation programs in patients with chronic diseases, as well as any characteristics that can be observed through the investigation. As a result, monitoring/tracking data were found to be the most common function in telerehabilitation portals. Data monitoring by patients allowed them to gain self-management skills, which is a key for controlling chronic diseases [11]. Moreover, portal 9 was called by the authors "A webpage for self-management." Those results indicate that fostering self-management skills is one of the characteristic features of telerehabilitation web portals. Another characteristic feature can be observed through a communication function, because patients with chronic symptoms often require a multidisciplinary care team, including patients' relatives [48,50]. Facilitating physical activities is another characteristic function of telerehabilitation portals, and exercise programs are often individually modified $[41,43,49,56,60,64]$. Nine portals embedded either audiovisual exercise instructions or exercise game contents, whereas ActivOnline, "A web portal" (portal 6), and "A web application" (portal 8) promote physical activity by a monitoring function. The TELEKAT portal and IBMS do not promote exercises directly; however, exercise promotion is included in a part of the TELEKAT intervention. As such, the web portals not only present rehabilitation instructions but also facilitate rehabilitation activities through various functional features. In other words, the underlying concept of web portals is to lower the hurdle and promote rehabilitation to become part of patients' everyday lives.

Taken together, we propose several key concepts that can be addressed in the development of a telerehabilitation web portal. The advantage of web portals is their ability to unify and provide various information, which can be shared by many stakeholders, including patients' relatives. By contrast, acquiring data and real-time correspondence often demand an extra system. Regarding the weakness of data acquisition and real-time correspondence, providing patients with a tablet or smartphone with a Bluetooth connection may help solve such problems, as exemplified in some studies $[30,40,43,48]$. Asynchronous than synchronous rehabilitation is more preferrable for web portals, as it is regarded as less time restrictive and more able to access a rehabilitation program [72-75]. This may suit rehabilitation participants who struggle with disruption to their established routine. The principle of patient-centered care may guide development of the digital platform. Consequently, conducting a participatory design process may be desirable. Theoretical approaches are recommended because theories and models can be used not only during the developing phase but also to analyze outcomes. Moreover, using a theoretical approach enables an intervention to be mapped to existing knowledge. Functional features may be developed upon the association of BCTs or MTs. In addition, other BCTs that were not observed in the 14 portals may be included in future telerehabilitation portals, for example, prompt barrier identification or mindfulness techniques
[70,76]. Many different kinds of digital platforms are currently available for telerehabilitation. Reasons for choosing certain platforms, such as web applications, iOS/Android apps, and eHealth device-associated applications, are considered to be knowledge gaps, which should be studied in the future. Differences in platforms can be analyzed from the perspective of data privacy issues. Because web portals often contain highly personal information, choosing a web application involves an important security strategy. Security updates of web applications are done by system providers, and, unlike native apps, little action is required from the user side. This is a great advantage for participants, especially those unfamiliar with digital technologies.

Theoretical approaches were found in more than half of the portals analyzed, and BCTs were often mentioned in those studies. Current knowledge of BCTs, however, may not be sufficient to understand BCTs used for telerehabilitation platforms. For instance, although monitoring/tracking data are associated with BCTs and MTs in several web portal articles $[30,31,59]$, the function is not monitoring behavior itself but rather monitoring physical condition or exercise performance. Developing a new analytical method for theories, BCTs, MTs, and mode of delivery used in telerehabilitation may provide evidence on which to base selection of particular combinations.

Web portals are not only practical tools to collect data or supply exercise instructions. If remote monitoring by health care professionals is the only goal, portals may not be necessary to be developed. Patients with chronic diseases often require lifestyle changes. Through patient-centered functions, web portals deliver various useful support for patients with chronic diseases. Web portals also assist rehabilitation to become part of patients' daily routines, which is considered a key to guiding successful disease management [44]. Web portals have the potential to facilitate patients in applying a new, healthy lifestyle in accordance with their symptoms and help participants master their own diseases in everyday life.

\section{Limitations}

International consensus about web portals for telerehabilitation is scarce. To effectively extract the characteristics, rather strict inclusion criteria were applied in this study. As mentioned in the "Methods" section, portals developed for purposes other than telerehabilitation were excluded, as were clinician portals, portals targeting other than chronic diseases, web applications designed for a single purpose, and web services with limited time of access. In this manner, we were able to bring out some characteristic features of web portals for telerehabilitation. We believe that our findings can be used in comparative studies of digital platforms of telerehabilitation in future investigations. Another limitation is that some of the projects described in this review are currently ongoing, suggesting that the functions of their portals may be improved in the future. Finally, this study did not include the cost of utilities, or patients' and health care professionals' experiences and perspectives when using the portals. 


\section{Conclusions}

Telerehabilitation has several advantages, including reducing the need to visit clinics by patients vulnerable to infectious diseases. The global COVID-19 pandemic has increased the need for telerehabilitation. Web portals have the potential to be a core digital component for patient-centered telerehabilitation. The common functional features of 14 web portals studied in this scoping review were monitoring/tracking data provided by 11 portals; communication, 10; exercise instructions, 9; diary/self-report functions, 9; relatives' participation, 6; goal settings, 5; and education, 5. Although different functional features addressed various purposes, the underlying concept was to facilitate rehabilitation to become a part of patients' everyday lives. Web portals were able to unify and display multiple types of data and could effectively provide various types of information. Asynchronous correspondence was more favorable than synchronous, real-time interactions. Data acquisition often demanded other digital tools. As much as 8 out of 14 portals employed theoretical approaches to some degree, and various patient-centered functions were observed. As is usual in web applications, security updates were the responsibility of service providers, and thus such platforms may be especially suitable for participants who are unfamiliar with digital technologies. These findings suggested that web portals for telerehabilitation not only provide entrance into rehabilitation programs but also reinforce patient-centered treatment, adherence to rehabilitation, and lifestyle changes over time.

\section{Acknowledgments}

This work was supported by a JSPS KAKENHI grant (20H04055). We thank Kenta Takahashi of Juntendo University Information Center for sharing his knowledge of computer science. We also thank Ai Nakahata of Juntendo University Academic Media Center (Library) for her professional assistance. Finally, we thank David Price and Swetha Anand for their help with the editorial preparation of the manuscript.

\section{Conflicts of Interest}

TT, NK, TK, and HD are affiliated with a department funded by Philips Japan; Asahi KASEI Corporation; Inter Reha Co, Ltd; and Toho Holdings Co, Ltd based on collaborative research agreements.

\section{Multimedia Appendix 1}

Descriptions of each portal.

[DOCX File, 34 KB-Multimedia Appendix 1]

\section{References}

1. World Health Organization (WHO). The World Health Report 2002 - Reducing Risks, Promoting Healthy Life. Geneva, Switzerland: WHO; 2002.

2. World Health Organization (WHO). Preventing Chronic Diseases - A Vital Investment. Geneva, Switzerland: WHO; 2005.

3. Richardson CR, Franklin B, Moy ML, Jackson EA. Advances in rehabilitation for chronic diseases: improving health outcomes and function. BMJ 2019 Jun 17;365:12191. [doi: 10.1136/bmj.12191] [Medline: 31208954]

4. Keating A, Lee A, Holland AE. What prevents people with chronic obstructive pulmonary disease from attending pulmonary rehabilitation? A systematic review. Chron Respir Dis 2011 May;8(2):89-99 [FREE Full text] [doi: 10.1177/1479972310393756] [Medline: 21596892]

5. Moulson N, Bewick D, Selway T, Harris J, Suskin N, Oh P, et al. Cardiac Rehabilitation During the COVID-19 Era: Guidance on Implementing Virtual Care. Can J Cardiol 2020;19:1317-1321. [doi: 10.1016/j.cjca.2020.06.006] [Medline: 32553606]

6. Leocani L, Diserens K, Moccia M, Caltagirone C. Disability through COVID - 19 pandemic: neurorehabilitation cannot wait. Eur J Neurol 2020 Jun 25:e50-e51. [doi: 10.1111/ene.14320] [Medline: 32402100]

7. Czeisler MÉ, Marynak K, Clarke KE, Salah Z, Shakya I, Thierry JM, et al. Delay or Avoidance of Medical Care Because of COVID-19-Related Concerns - United States, June 2020. MMWR Morb Mortal Wkly Rep 2020 Sep 11;69(36):1250-1257 [FREE Full text] [doi: 10.15585/mmwr.mm6936a4] [Medline: $\underline{\text { 32915166] }}$

8. Brennan D, Tindall L, Theodoros D, Brown J, Campbell M, Christiana D, et al. A blueprint for telerehabilitation guidelines. Int J Telerehabil 2010;2(2):31-34 [FREE Full text] [doi: 10.5195/ijt.2010.6063] [Medline: 25945175]

9. Cox N, Dal Corso S, Hansen H, McDonald C, Hill C, Zanaboni P, et al. Telerehabilitation for chronic respiratory disease. Cochrane Database Syst Rev 2021 Jan 29;1:CD013040. [doi: 10.1002/14651858.CD013040.pub2] [Medline: 33511633]

10. Laver K, Adey-Wakeling Z, Crotty M, Lannin N, George S. Telerehabilitation services for stroke. Cochrane Database Syst Rev 2020;1(1):CD010255. [doi: 10.1002/14651858.cd010255.pub3] [Medline: $\underline{\text { 32002991] }}$

11. Brouwers RWM, van Exel HJ, van Hal JMC, Jorstad HT, de Kluiver EP, Kraaijenhagen RA, Committee for Cardiovascular PreventionCardiac Rehabilitation of the Netherlands Society of Cardiology. Cardiac telerehabilitation as an alternative to centre-based cardiac rehabilitation. Neth Heart J 2020 Sep;28(9):443-451 [FREE Full text] [doi: 10.1007/s12471-020-01432-y] [Medline: $\underline{\text { 32495296] }}$ 
12. Choukou M, Maddahi A, Polyvyana A, Monnin C. Digital health technology for Indigenous older adults: A scoping review. Int J Med Inform 2021 Apr;148:104408. [doi: 10.1016/j.ijmedinf.2021.104408] [Medline: 33609927]

13. Saner H, van der Velde E. eHealth in cardiovascular medicine: A clinical update. Eur J Prev Cardiol 2016 Oct;23(2 suppl):5-12. [doi: 10.1177/2047487316670256] [Medline: 27892420]

14. Zasadzka E, Trzmiel T, Pieczyńska A, Hojan K. Modern Technologies in the Rehabilitation of Patients with Multiple Sclerosis and Their Potential Application in Times of COVID-19. Medicina (Kaunas) 2021 May 30;57(6):549 [FREE Full text] [doi: 10.3390/medicina57060549] [Medline: 34070705]

15. Oxford Learner's Dictionaries. URL: https://www.oxfordlearnersdictionaries.com/ [accessed 2022-01-18]

16. Hoogenbosch B, Postma J, de Man-van Ginkel JM, Tiemessen NA, van Delden JJ, van Os-Medendorp H. Use and the Users of a Patient Portal: Cross-Sectional Study. J Med Internet Res 2018 Sep 17;20(9):e262 [FREE Full text] [doi: 10.2196/jmir.9418] [Medline: 30224334]

17. Medical Dictionary. URL: https://medical-dictionary.thefreedictionary.com/ [accessed 2022-01-18]

18. What Is a Patient Portal?. 2021. URL: https://www.healthit.gov/faq/what-patient-portal [accessed 2022-01-18]

19. Van den Bulck SA, Hermens R, Slegers K, Vandenberghe B, Goderis G, Vankrunkelsven P. Designing a Patient Portal for Patient-Centered Care: Cross-Sectional Survey. J Med Internet Res 2018 Oct 01;20(10):e269 [FREE Full text] [doi: 10.2196/jmir.9497] [Medline: 30287416]

20. National Learning Consortium. How to Optimize Patient Portals for Patient Engagement and Meet Meaningful Use Requirements. 2013. URL: https://www.healthit.gov/sites/default/files/ nlc_how to_optimizepatientportals_for_patientengagement.pdf [accessed 2022-01-18]

21. Institute of Medicine (US) Committee on Quality of Health Care in America. Crossing the Quality Chasm: A New Health System for the 21st Century. Washington (DC): National Academies Press; 2001.

22. Gerteis M, Edgman-Levitan S, Daley J, Delbanco TL. Through the Patient's Eyes: Understanding and Promoting Patient-Centered Care. San Francisco, CA: Jossey-Bass; 2002.

23. Conroy SS, Harcum S, Keldsen L, Bever CT. Novel use of existing technology: A preliminary study of patient portal use for telerehabilitation. J Telemed Telecare 2020 Sep 01:1357633X20950172. [doi: 10.1177/1357633X20950172] [Medline: 32869689]

24. Tricco AC, Lillie E, Zarin W, O'Brien KK, Colquhoun H, Levac D, et al. PRISMA Extension for Scoping Reviews (PRISMA-ScR): Checklist and Explanation. Ann Intern Med 2018 Oct 02;169(7):467-473 [FREE Full text] [doi: 10.7326/M18-0850] [Medline: 30178033]

25. Preferred Reporting Items for Systematic Reviews and Meta-Analyses extension for Scoping Reviews (PRISMA-ScR) Checklist. URL: http://www.prisma-statement.org/documents/PRISMA-ScR-Fillable-Checklist_11Sept2019.pdf [accessed 2022-01-18]

26. Final Version of the Study Protocol. 2021 Jul. URL: https://osf.io/a457t/ [accessed 2022-01-18]

27. PubMed. URL: https://pubmed.ncbi.nlm.nih.gov/ [accessed 2022-01-18]

28. Web of Science. URL: https://apps.webofknowledge.com/ [accessed 2022-01-18]

29. Arksey H, O'Malley L. Scoping studies: towards a methodological framework. International Journal of Social Research Methodology 2005 Feb;8(1):19-32. [doi: 10.1080/1364557032000119616]

30. Tabak M, Vollenbroek-Hutten MM, van der Valk PD, van der Palen J, Hermens HJ. A telerehabilitation intervention for patients with Chronic Obstructive Pulmonary Disease: a randomized controlled pilot trial. Clin Rehabil 2014 Jun 29;28(6):582-591. [doi: 10.1177/0269215513512495] [Medline: 24293120]

31. Dinesen B, Huniche L, Toft E. Attitudes of COPD patients towards tele-rehabilitation: a cross-sector case study. Int J Environ Res Public Health 2013 Nov 15;10(11):6184-6198 [FREE Full text] [doi: 10.3390/ijerph10116184] [Medline: 24247995]

32. Haesum L, Soerensen N, Dinesen B, Nielsen C, Grann O, Hejlesen O, et al. Cost-utility analysis of a telerehabilitation program: a case study of COPD patients. Telemed J E Health 2012 Nov;18(9):688-692. [doi: 10.1089/tmj.2011.0250] [Medline: 23020647]

33. Dinesen B, Haesum LK, Soerensen N, Nielsen C, Grann O, Hejlesen O, et al. Using preventive home monitoring to reduce hospital admission rates and reduce costs: a case study of telehealth among chronic obstructive pulmonary disease patients. J Telemed Telecare 2012 Jun 31;18(4):221-225. [doi: 10.1258/jtt.2012.110704] [Medline: 22653618]

34. Jensen MH, Cichosz SL, Dinesen B, Hejlesen OK. Moving prediction of exacerbation in chronic obstructive pulmonary disease for patients in telecare. J Telemed Telecare 2012 Mar 20;18(2):99-103. [doi: 10.1258/jtt.2011.110607] [Medline: 22267305]

35. Dinesen B, Andersen S, Hejlesen O, Toft E. Interaction between COPD patients and healthcare professionals in a cross-sector tele-rehabilitation programme. Stud Health Technol Inform 2011;169:28-32. [Medline: 21893708]

36. Dinesen B, Seeman J, Gustafsson J. Development of a program for tele-rehabilitation of COPD patients across sectors: co-innovation in a network. Int J Integr Care 2011 Jan;11:e012 [FREE Full text] [doi: 10.5334/ijic.582] [Medline: 21637709]

37. Huniche L, Dinesen B, Grann O, Toft E, Nielsen C. Empowering patients with COPD using Tele-homecare technology. Stud Health Technol Inform 2010;155:48-54. [Medline: 20543309] 
38. Zanaboni P, Hoaas H, Aarøen Lien L, Hjalmarsen A, Wootton R. Long-term exercise maintenance in COPD via telerehabilitation: a two-year pilot study. J Telemed Telecare 2016 Jul 09;23(1):74-82. [doi: 10.1177/1357633x15625545] [Medline: 26888420]

39. Hoaas H, Andreassen HK, Lien LA, Hjalmarsen A, Zanaboni P. Adherence and factors affecting satisfaction in long-term telerehabilitation for patients with chronic obstructive pulmonary disease: a mixed methods study. BMC Med Inform Decis Mak 2016 Feb 25;16(1):26 [FREE Full text] [doi: 10.1186/s12911-016-0264-9] [Medline: 26911326]

40. Zanaboni P, Lien LA, Hjalmarsen A, Wootton R. Long-term telerehabilitation of COPD patients in their homes: interim results from a pilot study in Northern Norway. J Telemed Telecare 2013 Oct;19(7):425-429. [doi: 10.1177/1357633X13506514] [Medline: 24218358]

41. Tabak M, Brusse-Keizer M, van der Valk P, Hermens H, Vollenbroek-Hutten M. A telehealth program for self-management of COPD exacerbations and promotion of an active lifestyle: a pilot randomized controlled trial. Int J Chron Obstruct Pulmon Dis 2014;9:935-944 [FREE Full text] [doi: 10.2147/COPD.S60179] [Medline: 25246781]

42. Hoaas H, Zanaboni P, Hjalmarsen A, Morseth B, Dinesen B, Burge A, et al. Seasonal variations in objectively assessed physical activity among people with COPD in two Nordic countries and Australia: a cross-sectional study. Int J Chron Obstruct Pulmon Dis 2019;14:1219-1228 [FREE Full text] [doi: 10.2147/COPD.S194622] [Medline: $\underline{31239657]}$

43. Zanaboni P, Dinesen B, Hjalmarsen A, Hoaas H, Holland AE, Oliveira CC, et al. Long-term integrated telerehabilitation of COPD Patients: a multicentre randomised controlled trial (iTrain). BMC Pulm Med 2016 Aug 22;16(1):126 [FREE Full text] [doi: 10.1186/s12890-016-0288-z] [Medline: 27549782]

44. Dinesen B, Nielsen G, Andreasen JJ, Spindler H. Integration of Rehabilitation Activities Into Everyday Life Through Telerehabilitation: Qualitative Study of Cardiac Patients and Their Partners. J Med Internet Res 2019 Apr 15;21(4):e13281 [FREE Full text] [doi: 10.2196/13281] [Medline: 30985284]

45. Dinesen B, Spindler H. The Use of Telerehabilitation Technologies for Cardiac Patients to Improve Rehabilitation Activities and Unify Organizations: Qualitative Study. JMIR Rehabil Assist Technol 2018 Nov 19;5(2):e10758 [FREE Full text] [doi: 10.2196/10758] [Medline: $\underline{30455168]}$

46. Melholt C, Joensson K, Spindler H, Hansen J, Andreasen JJ, Nielsen G, et al. Cardiac patients' experiences with a telerehabilitation web portal: Implications for eHealth literacy. Patient Educ Couns 2018 May;101(5):854-861. [doi: 10.1016/j.pec.2017.12.017] [Medline: 29305064]

47. Joensson K, Melholt C, Hansen J, Leth S, Spindler H, Olsen M, et al. Listening to the patients: using participatory design in the development of a cardiac telerehabilitation web portal. Mhealth 2019;5:33 [FREE Full text] [doi:

10.21037/mhealth.2019.08.06] [Medline: $\underline{31620460 \text { ] }}$

48. Dinesen B, Dittmann L, Gade J, Jørgensen CK, Hollingdal M, Leth S, et al. "Future Patient" Telerehabilitation for Patients With Heart Failure: Protocol for a Randomized Controlled Trial. JMIR Res Protoc 2019 Sep 19;8(9):e14517 [FREE Full text] [doi: 10.2196/14517] [Medline: $\underline{31538944]}$

49. Brouwers RWM, Kraal JJ, Traa SCJ, Spee RF, Oostveen LMLC, Kemps HMC. Effects of cardiac telerehabilitation in patients with coronary artery disease using a personalised patient-centred web application: protocol for the SmartCare-CAD randomised controlled trial. BMC Cardiovasc Disord 2017 Dec 31;17(1):46 [FREE Full text] [doi: 10.1186/s12872-017-0477-6] [Medline: 28143388]

50. Voigt I, Benedict M, Susky M, Scheplitz T, Frankowitz S, Kern R, et al. A Digital Patient Portal for Patients With Multiple Sclerosis. Front Neurol 2020;11:400 [FREE Full text] [doi: 10.3389/fneur.2020.00400] [Medline: $\underline{32670174]}$

51. Eguiluz-Perez G, Garcia-Zapirain B. Comprehensive verticality analysis and web-based rehabilitation system for people with multiple sclerosis with supervised medical monitoring. Biomed Mater Eng 2014;24(6):3493-3502. [doi: 10.3233/BME-141175] [Medline: 25227062]

52. Kloek CJ, Bossen D, de Vries HJ, de Bakker DH, Veenhof C, Dekker J. Physiotherapists' experiences with a blended osteoarthritis intervention: a mixed methods study. Physiother Theory Pract 2020 May 28;36(5):572-579. [doi: 10.1080/09593985.2018.1489926] [Medline: 29952687]

53. Kloek CJJ, van Dongen JM, de Bakker DH, Bossen D, Dekker J, Veenhof C. Cost-effectiveness of a blended physiotherapy intervention compared to usual physiotherapy in patients with hip and/or knee osteoarthritis: a cluster randomized controlled trial. BMC Public Health 2018 Aug 31;18(1):1082 [FREE Full text] [doi: 10.1186/s12889-018-5975-7] [Medline: 30170586]

54. Kloek CJJ, Bossen D, Spreeuwenberg PM, Dekker J, de Bakker DH, Veenhof C. Effectiveness of a Blended Physical Therapist Intervention in People With Hip Osteoarthritis, Knee Osteoarthritis, or Both: A Cluster-Randomized Controlled Trial. Phys Ther 2018 Jul 01;98(7):560-570 [FREE Full text] [doi: 10.1093/ptj/pzy045] [Medline: 29788253]

55. de VHJ, Kloek CJJ, de BDH, Dekker J, Bossen D, Veenhof C. Determinants of Adherence to the Online Component of a Blended Intervention for Patients with Hip and/or Knee Osteoarthritis: A Mixed Methods Study Embedded in the e-Exercise Trial. Telemed J E Health 2017 Dec;23(12):1002-1010. [doi: 10.1089/tmj.2016.0264] [Medline: 28525310]

56. Bossen D, Kloek C, Snippe HW, Dekker J, de Bakker D, Veenhof C. A Blended Intervention for Patients With Knee and Hip Osteoarthritis in the Physical Therapy Practice: Development and a Pilot Study. JMIR Res Protoc 2016 Feb 24;5(1):e32 [FREE Full text] [doi: 10.2196/resprot.5049] [Medline: 26912378]

57. Cox NS, Eldridge B, Rawlings S, Dreger J, Corda J, Hauser J, Youth Activity Unlimited - A Strategic Research Centre of the UK Cystic Fibrosis Trust. A web-based intervention to promote physical activity in adolescents and young adults with 
cystic fibrosis: protocol for a randomized controlled trial. BMC Pulm Med 2019 Dec 19;19(1):253 [FREE Full text] [doi: 10.1186/s12890-019-0942-3] [Medline: $\underline{31856791]}$

58. Liacos A, Burge A, Cox N, Holland AE. Promoting Physical Activity Using the Internet: Is It Feasible and Acceptable for Patients With Chronic Obstructive Pulmonary Disease and Bronchiectasis? J Aging Phys Act 2018 Jul 01;26(3):372-381. [doi: 10.1123/japa.2017-0123] [Medline: 28952865]

59. Cox NS, Alison JA, Button BM, Wilson JW, Holland AE. Feasibility and acceptability of an internet-based program to promote physical activity in adults with cystic fibrosis. Respir Care 2015 Mar;60(3):422-429 [FREE Full text] [doi: 10.4187/respcare.03165] [Medline: 25425703]

60. Burridge JH, Lee ACW, Turk R, Stokes M, Whitall J, Vaidyanathan R, et al. Telehealth, Wearable Sensors, and the Internet: Will They Improve Stroke Outcomes Through Increased Intensity of Therapy, Motivation, and Adherence to Rehabilitation Programs? J Neurol Phys Ther 2017 Jul;41 Suppl 3:S32-S38. [doi: 10.1097/NPT.0000000000000183] [Medline: 28628594]

61. Ariza-Garcia A, Lozano-Lozano M, Galiano-Castillo N, Postigo-Martin P, Arroyo-Morales M, Cantarero-Villanueva I. A Web-Based Exercise System (e-CuidateChemo) to Counter the Side Effects of Chemotherapy in Patients With Breast Cancer: Randomized Controlled Trial. J Med Internet Res 2019 Jul 24;21(7):e14418 [FREE Full text] [doi: 10.2196/14418] [Medline: $\underline{31342907]}$

62. Galiano-Castillo N, Arroyo-Morales M, Lozano-Lozano M, Fernández-Lao C, Martín-Martín L, Del-Moral-Ávila R, et al. Effect of an Internet-based telehealth system on functional capacity and cognition in breast cancer survivors: a secondary analysis of a randomized controlled trial. Support Care Cancer 2017 Nov 22;25(11):3551-3559. [doi: 10.1007/s00520-017-3782-9] [Medline: 28639097]

63. Galiano-Castillo N, Cantarero-Villanueva I, Fernández-Lao C, Ariza-García A, Díaz-Rodríguez L, Del-Moral-Ávila R, et al. Telehealth system: A randomized controlled trial evaluating the impact of an internet-based exercise intervention on quality of life, pain, muscle strength, and fatigue in breast cancer survivors. Cancer 2016 Oct 15;122(20):3166-3174 [FREE Full text] [doi: 10.1002/cncr.30172] [Medline: 27332968]

64. Galiano-Castillo N, Ariza-García A, Cantarero-Villanueva I, Fernández-Lao C, Díaz-Rodríguez L, Legerén-Alvarez M, et al. Telehealth system (e-CUIDATE) to improve quality of life in breast cancer survivors: rationale and study protocol for a randomized clinical trial. Trials 2013 Jun 22;14:187 [FREE Full text] [doi: 10.1186/1745-6215-14-187] [Medline: $\underline{23799886}]$

65. Norman CD, Skinner HA. eHealth Literacy: Essential Skills for Consumer Health in a Networked World. J Med Internet Res 2006 Jun 16;8(2):e9 [FREE Full text] [doi: 10.2196/jmir.8.2.e9] [Medline: 16867972]

66. Wenger E. Communities of Practice: Learning, Meaning, and Identity (Learning in Doing: Social, Cognitive and Computational Perspectives). Cambridge, MA: Cambridge University Press; 1999.

67. Ryan RM, Deci EL. Self-determination theory and the facilitation of intrinsic motivation, social development, and well-being. American Psychologist 2000;55(1):68-78. [doi: 10.1037//0003-066X.55.1.68]

68. Schlieter H, Benedict M, Gand K, Burwitz M. Towards Adaptive Pathways: Reference Architecture for Personalized Dynamic Pathways. 2017 Presented at: IEEE 19th Conference on Business Informatics (CBI); July 24-27, 2017; Thessaloniki, Greece p. 359-368. [doi: 10.1109/cbi.2017.55]

69. Yardley L, Morrison L, Bradbury K, Muller I. The person-based approach to intervention development: application to digital health-related behavior change interventions. J Med Internet Res 2015 Jan 30;17(1):e30 [FREE Full text] [doi: 10.2196/jmir.4055] [Medline: 25639757]

70. Abraham C, Michie S. A taxonomy of behavior change techniques used in interventions. Health Psychol 2008 May;27(3):379-387. [doi: 10.1037/0278-6133.27.3.379] [Medline: 18624603]

71. Webb TL, Joseph J, Yardley L, Michie S. Using the internet to promote health behavior change: a systematic review and meta-analysis of the impact of theoretical basis, use of behavior change techniques, and mode of delivery on efficacy. J Med Internet Res 2010 Feb 17;12(1):e4 [FREE Full text] [doi: 10.2196/jmir.1376] [Medline: 20164043]

72. Bini S, Mahajan J. Clinical outcomes of remote asynchronous telerehabilitation are equivalent to traditional therapy following total knee arthroplasty: A randomized control study. J Telemed Telecare 2017 Feb;23(2):239-247. [doi: 10.1177/1357633X16634518] [Medline: 26940798]

73. Naeemabadi M, Dinesen B, Andersen OK, Madsen NK, Simonsen OH, Hansen J. Developing a telerehabilitation programme for postoperative recovery from knee surgery: specifications and requirements. BMJ Health Care Inform 2019 Apr;26(1):e000022 [FREE Full text] [doi: 10.1136/bmjhci-2019-000022] [Medline: 31039126]

74. Naeemabadi M, Søndergaard JH, Klastrup A, Schlünsen AP, Lauritsen REK, Hansen J, et al. Development of an individualized asynchronous sensor-based telerehabilitation program for patients undergoing total knee replacement: Participatory design. Health Informatics J 2020 Dec;26(4):2492-2511 [FREE Full text] [doi: 10.1177/1460458220909779] [Medline: $\underline{\text { 32175788] }}$

75. Naeemabadi M, Fazlali H, Najafi S, Dinesen B, Hansen J. Telerehabilitation for Patients With Knee Osteoarthritis: A Focused Review of Technologies and Teleservices. JMIR Biomed Eng 2020 Jul 21;5(1):e16991. [doi: 10.2196/16991]

76. Schuman-Olivier Z, Trombka M, Lovas DA, Brewer JA, Vago DR, Gawande R, et al. Mindfulness and Behavior Change. Harv Rev Psychiatry 2020;28(6):371-394 [FREE Full text] [doi: 10.1097/HRP.0000000000000277] [Medline: 33156156] 


\section{Abbreviations}

ActionPACT: the active online physical activity in the cystic fibrosis trial

BCT: behavior change technique

COPD: chronic obstructive pulmonary disease

IBMS: integrated care portal multiple sclerosis

PRISMA-ScR: Preferred Reporting Items for Systematic Reviews and Meta-analysis Extension for Scoping

Reviews

PROs: patient-reported outcomes

TELEKAT: telehomecare, chronic patients, and the integrated health care system

TTP: teledialog telerehabilitation program

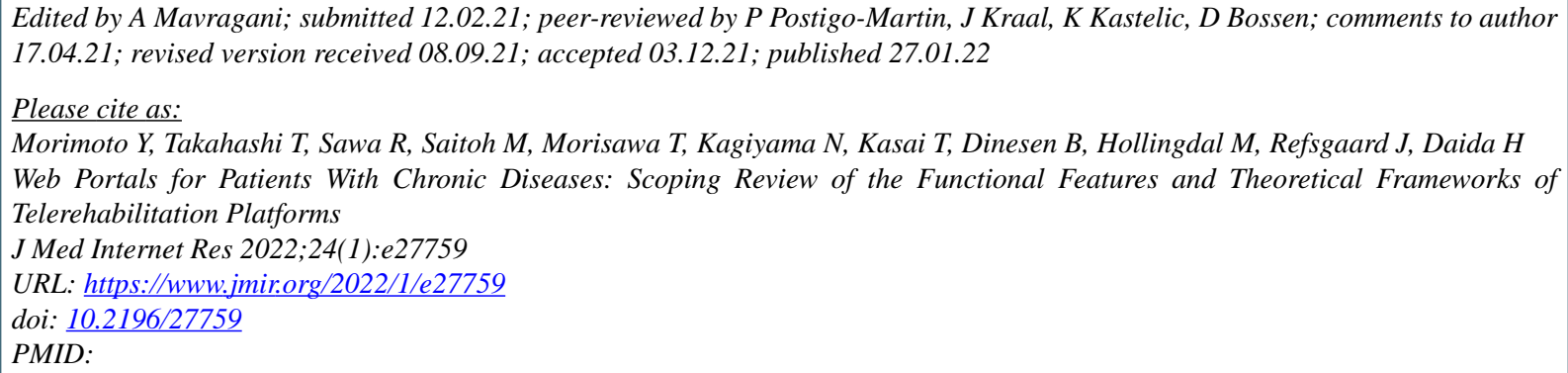

(C) Yuh Morimoto, Tetsuya Takahashi, Ryuichi Sawa, Masakazu Saitoh, Tomoyuki Morisawa, Nobuyuki Kagiyama, Takatoshi Kasai, Birthe Dinesen, Malene Hollingdal, Jens Refsgaard, Hiroyuki Daida. Originally published in the Journal of Medical Internet Research (https://www.jmir.org), 27.01.2022. This is an open-access article distributed under the terms of the Creative Commons Attribution License (https://creativecommons.org/licenses/by/4.0/), which permits unrestricted use, distribution, and reproduction in any medium, provided the original work, first published in the Journal of Medical Internet Research, is properly cited. The complete bibliographic information, a link to the original publication on https://www.jmir.org/, as well as this copyright and license information must be included. 